\title{
Maternal Knowledge, Attitudes and Practices Regarding Dietary Fats
}

\author{
Nădășan Valentin*, Sîmpetrean Andreea, Tarcea Monica, Abram Zoltan \\ University of Medicine and Pharmacy of Tirgu Mures, Romania
}

\begin{abstract}
Objective: The purpose of the study was to assess the knowledge, attitudes, and behavior regarding dietary fats among mothers in Romania. Material and methods: A sample of 305 mothers from Romania were included in a cross-sectional observational study. The online questionnaire addressed their knowledge, attitudes, and practices regarding the dietary fats used in their children's diet. The frequencies and proportions of the collected variables were calculated based on respondents' answers. Results: While almost all the respondents (94.8\%) believed that mothers are supposed to know the difference between saturated and unsaturated fats, only less than half of them (39.7\%) stated that they know the difference. As far as the types of margarine, although more than half of the respondents (64.7\%) believed that mothers should be able to discriminate between the hydrogenated and interesterified margarine, only $11.5 \%$ claimed that they are able to discern between them. The actual ability to identify foods rich in saturated fats varied in a great degree from item to item. More common dietary fats such as sunflower oil, corn oil, and lard, were more frequently identified than less common dietary fats such as coconut oil and palm oil. Only $16.4 \%$ of the mothers were able to correctly differentiate hydrogenated from interesterified margarine. The most frequently used spreadable fat used in the children's diet was butter and the most frequently used cooking fats were sunflower oil, olive oil, and butter. Conclusion: The results of this study might be informative in the development of maternal nutrition education programs.
\end{abstract}

Keywords: nutrition literacy, dietary fats, mothers, children

Received: 01 September 2016 / Accepted: 12 September 2016

\section{Introduction}

Dietary fats are indispensable for growth, development, and normal functioning of the human body. They are an important source of energy, provide a large array of structural building blocks, play a role as fat-soluble vitamin carriers and intervene as essential components in many biological functions. Moreover, deficient or excess dietary fat consumption has a number of health-related outcomes.

Obesity in adults and children is a major public health concern in many high-income and developing countries $[1,2]$. While the role of dietary fats as an independent risk factor in obesity is still debated, it is largely recognized that they have a major contribution to this metabolic condition by increasing the energy density of food and thus facilitating excessive calory intake [3-5].

Dietary fats are also significant risk and protective factors for cardiovascular disease (CVD). An increased dietary intake of saturated fatty acids is associated with increased risk of CVD and reversely, a decreased saturated fatty acids intake combined with an increased polyunsaturated and monounsaturated fatty acids intake but without increasing total dietary fat intake is associated with a reduced CVD risk [6-9]. N-3 and n-6 polyunsaturated fatty acids are inversely associated with CVD risk [10]. Trans fatty acids from hydrogenated vegetable oils are associated not only with a higher risk of CVD but also with low-grade inflammation that may lead to decreased insulin sensitivity and

* Correspondence to: Valentin Nădășan

E-mail: valentin.nadasan@umftgm.ro development of type 2 diabetes especially in susceptible individuals $[7,11]$.

Chronic excess energy intake is associated with insulin resistance which is a key determinant in the development of type 2 diabetes mellitus [12]. Although the place of saturated dietary fats in the etiology of type 2 diabetes mellitus has been challenged in recent years, data from observational controlled experimental studies suggesting that replacing saturated and trans fatty acids with polyunsaturated fatty acids can lower the risk of type 2 diabetes can not be ignored $[13,14]$. A substantial amount of evidence, suggests that many foods especially dietary fats may affect inflammatory processes both acutely and chronically and low-grade inflammation is suspected to be involved in the cardiometabolic syndrome, increased risk of type 2 diabetes mellitus and cardiovascular disease associated with obesity [15].

Finally, while the deficiency of alpha-linolenic acid has been linked to neurological abnormalities and poor growth, an optimal consumption of docosahexaenoic acid, the predominant omega-3 polyunsaturated fatty acid found in the brain, has been positively associated with beneficial effects on brain development during childhood and cognitive performance in the adult life $[16,17]$.

Food intake patterns are developed in the very first years of childhood [18] and the family environment has a profound impact on children's food and activity preferences [19-21]. Although the link between maternal nutritional literacy and the nutritional status of the children in their care was reported by some authors [22,23] and parents are seen as a primary target of childhood obesity preven- 
tion programs [24], few studies have investigated maternal knowledge, attitudes and behavior regarding dietary fats.

The purpose of the study was to assess the knowledge, attitudes, and behavior regarding dietary fats among mothers in Romania.

\section{Methods}

The study was designed as a cross-sectional observational study. Participants were enrolled by posting an invitation on several women's online forums, social networking groups, and also by snowball emailing. The inclusion criterion was being the mother of at least one child.

Data collection was performed using an online questionnaire that was completed anonymously during 01.10.05.11.2013. After removing duplicate and incomplete data sets, the final analytical sample included 305 participants.

The questionnaire included questions covering demographic characteristics (age, place of residence, educational achievement, children's age) and the mothers' knowledge, attitudes and practices regarding the dietary fats used in the children's diet.

The frequencies and proportions of the collected variables were calculated based on respondents' answers.

\section{Results}

The mean age of the respondents was 31.8 years $(\mathrm{SD} \pm 4.3)$. As far as residence is concerned, $276(90.5 \%)$ of the participants were from urban and $29(9.5 \%)$ from rural areas. In terms of educational achievement, 40 (22.1\%) had undergraduate and 265 (86.9\%), graduate education. The number of children ranged between 1 and 3 for a mother and the average age of the children was 3.4 years.

Perceived social norm and perceived knowledge regarding dietary fats among the Romanian mothers included in the sample are presented in table I.

The ability of mothers to identify food with high/low saturated fat content and to differentiate between hydrogenated / interesterified margarine is represented in figure 1 .

The frequency of using various spreadable fats in the children's diet among Romanian mothers is shown in figure 2 .

Table I. Maternal perceived social norm and perceived knowledge regarding dietary fats

\begin{tabular}{lcc}
\hline & \multicolumn{2}{c}{ Answers (N=305), (\%) } \\
\cline { 2 - 3 } Questions & Yes & No or Not sure \\
\hline $\begin{array}{l}\text { Do you think mothers should know the } \\
\text { difference between saturated and }\end{array}$ & $289(94.8 \%)$ & $16(5.2 \%)$ \\
$\begin{array}{l}\text { unsaturated dietary fats? } \\
\begin{array}{l}\text { Do you think mothers should know the } \\
\text { difference between hydrogenated (old type) } \\
\text { and interesterified (new type) margarine? }\end{array}\end{array}$ & $198(64.9 \%)$ & $107(35.1 \%)$ \\
$\begin{array}{l}\text { Do you know the difference between } \\
\text { saturated and unsaturated dietary fats? }\end{array}$ & $121(39.7 \%)$ & $184(60.3 \%)$ \\
$\begin{array}{l}\text { Do you know the difference between } \\
\text { hydrogenated (old type) and interesterified } \\
\text { (new type) margarine? }\end{array}$ & $35(11.5 \%)$ & $270(88.5 \%)$ \\
\hline
\end{tabular}

The frequency of using various cooking fats when preparing food for their children, among Romanian mothers is represented in figure 3.

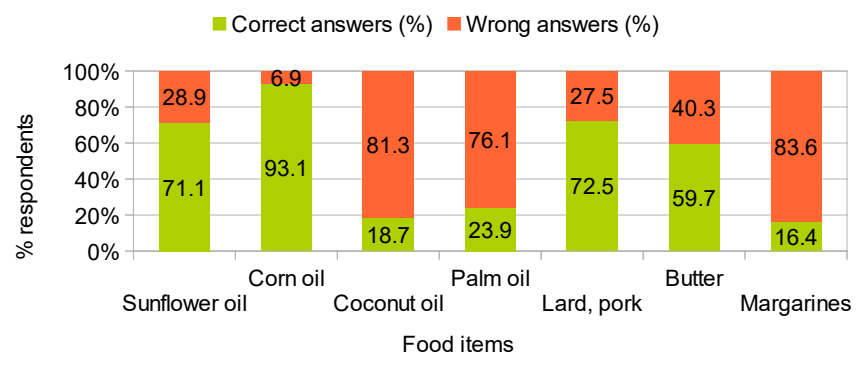

Fig. 1. The proportion of mothers able to identify foods with high/ low saturated fat content and to differentiate hydrogenated from interesterified margarine.

\section{Never or less than once a week One to three times a week \\ - One or more times a day}

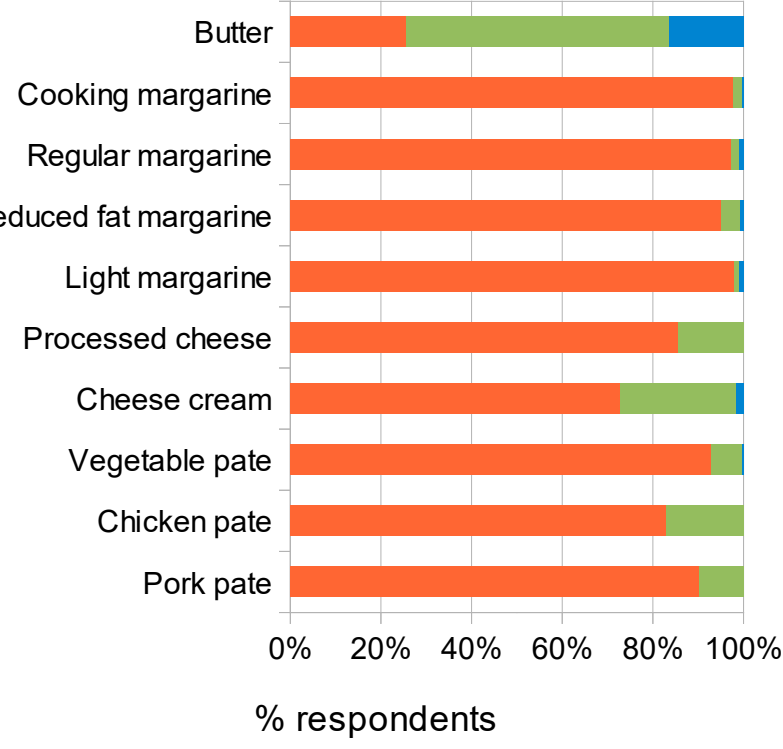

Fig. 2. The frequency of using various spreadable fats in the children's diet

Never or rarely Every now and then $\square$ Usually or always

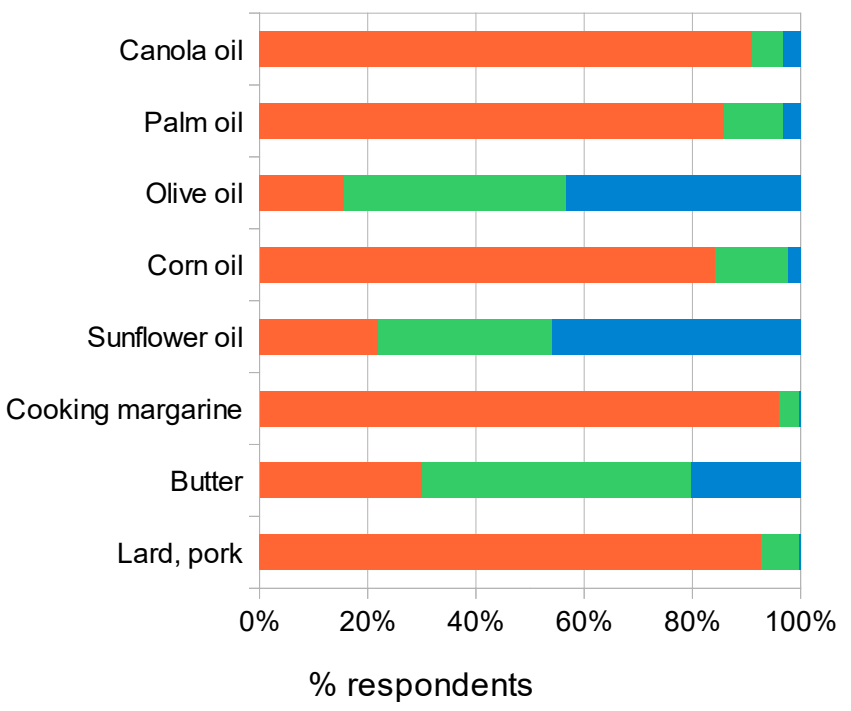

Fig. 3. The frequency of using various cooking fats for children's meals 


\section{Discussions}

This is the first research assessing knowledge, attitudes and practices regarding dietary fats among Romanian mothers. The study brings new knowledge about the nutritional literacy of a special group of people.

The very high percentage $(94.75 \%)$ of respondents who think it is important for a mother to know the difference between saturated and unsaturated fats, probably reflects a high concern for the child's nutrition. Among the factors that could explain such a largely shared attitude could be the increased popularity of nutrition in today's society, as reflected by the volume and the high emotional load of messages related to diet and food disseminated on the web and traditional mass media [25,26].

The proportion of mothers who stated that they know the difference between saturated and unsaturated fats is relatively low $(<40 \%)$, especially considering that the great majority of respondents had graduate studies.

The ability of the respondent mothers to identify correctly foods rich in saturated fats varied within a large range. As expected, more common dietary fats such as sunflower oil, corn oil, and lard, were more frequently identified than less common dietary fats such as coconut oil and palm oil. The respondents observed performance in identifying food items according to their content in saturated fat could be a concern since maternal nutrition literacy can have an important impact on the mothers' feeding practices and these are recognized as determinants of the children's short and long-term health status.

Studies in the USA have shown that most people (95\% of the population) have heard about saturated fats but only $78 \%$ of them were aware that this type of fat can increase cardiovascular disease risk [27]. Another research on adults in North America has shown that while $80 \%$ of the respondents could identify fatty foods in general, only $60 \%$ of them were able to identify foods with high saturated fat content from a given list of foods [28].

As far as the margarine is concerned, although more than half of the mothers recognized that is important to discern between the two basic types of this food product, very few of them $(11.8 \%)$ declared that they know the difference between hydrogenated and interesterified margarine, in spite of the fact that most mothers had University degree education. The ability of the respondent mothers to distinguish between hydrogenated and interesterified margarine seems rare in the studied sample. It is interesting to notice that more than half of them acknowledged that they simply don't know how to differentiate the specific types of margarine. Studies in the USA have shown that $92 \%$ of the respondents have heard about hydrogenated margarine and $73 \%$ of them are aware of its harmful effects on cardiovascular health [29]. On the other hand, only $21 \%$ of the respondents, were able to list three food items which contain hydrogenated fats [29].

As far as the use of spreadable fats in the children's diet, our data revealed that most mothers avoid all types of mar- garine, processed cheeses, and patés while frequently use butter, in spite of its high saturated fat content. Regarding the use of fats in cooking for their children, most mothers reported that they always or usually use sunflower oil, olive oil, and butter while corn oil, margarine, and lard are almost completely avoided.

Low levels of general nutrition literacy including dietary fats might be related to the widespread dissemination of poor quality or even misleading nutritional information through the internet, social networks, and mass-media [30,31].

The high level of concern with dietary fats observed among the Romanian mothers might be indicative of openness to participating in nutrition education programs addressing the topic of interest. The discrepancies observed in our study between perceived social norms regarding maternal knowledge of dietary fats, perceived knowledge and the actual ability to identify specific food items with high saturated or unsaturated fat content need further study in order to better understand how perceived social norms and knowledge regarding certain foods translate into dietary practices. Also, gaining knowledge in this respect could help in the development of efficient nutrition education programs specifically targeted.

Although there are several methodological limitations to our study (convenience sampling, self-selection of respondents, the use of the online questionnaire, recall bias etc.) the results could be useful in guiding future research on a representative sample as well as in tailoring nutrition education programs addressing the needs of Romanian mothers.

\section{Conclusion}

While perceived social norms regarding the mothers' knowledge about dietary fats were high, perceived knowledge of dietary fats and the actual ability to identify foods by their fat content were generally low among the mothers included in the investigated sample.

The results of this study might be informative in the development of maternal nutrition education programs.

\section{Conflict of interest}

None to declare.

\section{References}

1. Caballero B. The global epidemic of obesity: an overview. Epidemiol Rev. 2007;29:1-5. doi: 10.1093/epirev/mxm012.

2. James WP. WHO recognition of the global obesity epidemic. Int $\mathrm{J}$ Obes (Lond). doi: 10.1038/ijo.2008.247.

3. Ebbeling CB, Swain JF, Feldman HA, et al. Effects of dietary composition on energy expenditure during weight-loss maintenance. JAMA. 2012;307(24):2627-2634. doi: 10.1001/jama.2012.6607.

4. Tobias DK, Chen M, Manson JE, Ludwig DS, Willett W, Hu FB. Effect of low-fat diet interventions versus other diet interventions on long-term weight change in adults: a systematic review and meta-analysis. Lancet Diabetes Endocrinol. 2015;3:968-79.

5. National Heart Foundation of Australia. A review of the relationship between dietary fat and overweight/obesity. 2003. [Online] Available at URL: https://heartfoundation.org.au/images/uploads/publications/ Dietary-fat-ovob-Review.pdf Accessed: 11.08.2016. 
6. Michas G, Micha R, Zampelas A. Dietary fats and cardiovascular disease: putting together the pieces of a complicated puzzle. Atherosclerosis. 2014;234(2):320-328. doi: 10.1016/j.atherosclerosis.2014.03.013.

7. Guasch-Ferré M, Babio N, Martínez-González MA, et al. Dietary fat intake and risk of cardiovascular disease and all-cause mortality in a population at high risk of cardiovascular disease. Am J Clin Nutr. 2015;102(6):15631573. doi: 10.3945/ajcn.115.116046.

8. Kris-Etherton PM, Fleming JA. Emerging nutrition science on fatty acids and cardiovascular disease: nutritionists' perspectives. Adv Nutr. 2015;6:326S-337S. doi: 10.3945/ an.114.006981.

9. Hooper L, Summerbell CD, Thompson R, et al. Reduced or modified dietary fat for preventing cardiovascular disease. Cochrane Database Syst Rev. 2012;(5):CD002137. doi: 10.1002/14651858.CD002137.

10. Michas G, Micha R, Zampelas A. Dietary fats and cardiovascular disease: putting together the pieces of a complicated puzzle. Atherosclerosis. 2014;234(2):320-328. doi: 10.1016/j.atherosclerosis.2014.03.013.

11. de Souza RJ, Mente A, Maroleanu A, et al. Intake of saturated and trans unsaturated fatty acids and risk of all cause mortality, cardiovascular disease, and type 2 diabetes: systematic review and meta-analysis of observational studies. BMJ. 2015;351:h3978. doi: 10.1111/hex.12198.

12. Gupta D, Krueger CB, Lastra G. Over-nutrition, obesity and insulin resistance in the development of $\beta$-cell dysfunction. Curr Diabetes Rev. 2012;8:76-83.

13. Morio B, Fardet A, Legrand P, Lecerf JM. Involvement of dietary saturated fats, from all sources or of dairy origin only, in insulin resistance and type 2 diabetes. Nutr Rev. 2016;74:33-47. doi: 10.1093/nutrit/nuv043.

14. Risérus U, Willett WC, HuFB. Dietary fats and prevention of type 2 diabetes. Prog Lipid Res. 2009;48:44-51. doi: 10.1016/j.plipres.2008.10.002.

15. Minihane AM, Vinoy S, Russell WR, et al. Low-grade inflammation, diet composition and health: current research evidence and its translation. $\mathrm{Br}$ J Nutr. 2015;114:999-1012. doi: 10.1017/S0007114515002093.

16. Lauritzen L, Brambilla P, Mazzocchi A, et al. DHA Effects in Brain Development and Function. Nutrients. doi: 10.1017/ S0007114515002093.

17. Weiser MJ, Butt CM, Mohajeri MH. Docosahexaenoic Acid and Cognition throughout the Lifespan. Nutrients. 2016;8:99. doi: 10.3390/nu8020099

18. Johnson SL. Developmental and Environmental Influences on Young Children's Vegetable Preferences and Consumption. Adv Nutr. 2016;7:220S-31S. doi: 10.3390/nu8020099.

19. Birch LL, Davison KK. Family environmental factors influencing the developing behavioral controls of food intake and childhood overweight. Pediatr Clin North Am. 2001;48:893-907.

20. Al-Shookri A, Al-Shukaily L, Hassan F, Al-Sheraji S, Al-Tobi S. Effect of Mothers Nutritional Knowledge and Attitudes on Omani Children's Dietary Intake. Oman Med J. 2011;26(4):253-257. doi: 10.5001/omj.2011.61.

21. Scaglioni S, Salvioni M, Galimberti C. Influence of parental attitudes in development of children eating behaviour. $\mathrm{Br} J$ Nutr. 2008;99 Suppl1:S22-25. doi: 10.1017/S0007114508892471.

22. Saaka M. Relationship between mothers' nutritional knowledge in childcare practices and the growth of children living in impoverished rural communities. J Health Popul Nutr. 2014;32:237-248.

23. Appoh LY, Krekling S. Maternal nutritional knowledge and child nutritional status in the Volta region of Ghana. Matern Child Nutr. 2005;1:100-110.

24. Scaglioni S, Arrizza C, Vecchi F, Tedeschi S. Determinants of children's eating behavior. Am J Clin Nutr. 2011;94(6 Suppl):2006S-2011S. doi: 10.3945/ajcn.110.001685

25. Academy of Nutrition and Dietetics. Nutrition and You: Trends 2011. Public Opinion on Food and Nutrition: 20 Years of Insights, [Online] www. eatright.org/Media/content.aspx?id=7639\#.U8eSv_kbUqE Accessed: 17.07.2014.

26. Cash T, Desbrow B, Leveritt M, Ball L. Utilization and preference of nutrition information sources in Australia. Health Expect. 2015;18:22882295. doi: 10.1111/hex.12198.

27. Lin CT, Yen ST. Knowledge of dietary fats among US consumers. J Am Diet Assoc, 2010;110:613-618. doi: 10.1016/j.jada.2009.12.020.

28. Guthrie JF, Derby BM, Levy AS. What people know and do not know about nutrition. Chapter 13. In: Frazao E (ed). America's Eating Habits: Changes and consequences [online]. Washington, DC: Economic Research Service.1999. pg. 243-278.

29. Eckel RH, Kris-Etherton P, Lichtenstein AH, et al. Americans' awareness, knowledge, and behaviors regarding fats: 2006-2007. J Am Diet Assoc. 2009;109:288-296. doi: 10.1016/j.jada.2008.10.048.

30. Nagler $\mathrm{RH}$. Adverse outcomes associated with media exposure to contradictory nutrition messages. J Health Commun. 2014;19:24-40. doi: 10.1080/10810730.2013.798384.

31. Nădășan V, Vancea G, Georgescu AP, Tarcea M, Abram Z. The Credibility, Completeness and Accuracy of Information about First Aid in Case of Choking on the Romanian Websites. Journal of Applied Quantitative Methods 2011;6:18-26. 